\title{
THE FUTURE OF LOCAL WASTE MATERIAL UTILIZATION IN DISTRIBUTED ENERGY PRODUCTION IN FINLAND
}

\author{
Mika Horttanainen \\ Mika Luoranen \\ Niko Eriksson \\ Lappeenranta University of Technology, Finland
}

\begin{abstract}
A very small part of waste management has been carried out by incineration in Finland. About $300 \mathrm{kt}$ of waste is incinerated or burned with other fuels. Waste materials have been used in energy production mostly as co-combustion fuels at several energy production plants.

The waste incineration directive of the European Union sets tight regulations for the emission limits, their measurements, as well as for temperature and residence time conditions in the furnace. The costs of solid recovered fuel (SRF) utilization will increase remarkably especially in small heating plants because of these demands.

In this study we focus on the preconditions for the utilization of local waste materials in distributed energy production. We introduce two different cases where a fuel produced from local waste materials is used in small-scale energy production $(<10 \mathrm{MW})$. The first case includes an existing 3.5 MW district heating boiler which has used SRF with biofuels for several years with good experiences and low emissions. The fraction of SRF is only about 10 $\%$ of the total fuel. The second case is based on package and construction waste collected from the economic area of about 75000 people. It was assumed that the technology of the new heating plant would not have to differ a lot from the modern biofuel-using plant because of the good SRF quality. The amount of the waste-derived fuel is $10000 \mathrm{t} / \mathrm{a}$.

In the first case the continuation of the energy use of waste would cause at least a $38 \%$ rise to the waste management fee. In the second case the investment and operation costs could be covered without a gate-fee if the owner of the plant (e.g. a sawmill) could save about 25 $€ / \mathrm{MWh}$ (approximate price of heat for customer) in the purchase costs of heat for their own consumption. If the plant could sell the heat to the district heating network with the price of $15.5 \mathrm{E} / \mathrm{MWh}$, the gate-fee would be about $38 € / \mathrm{t}$ at the break-even point, which is the same as the gate-fee of the energy waste at the moment.
\end{abstract}

\section{KEYWORDS}

Waste to energy; Distributed energy systems 


\section{INTRODUCTION}

A very small part of waste management has been carried out by incineration in Finland. About $260000 \mathrm{t}$ of waste was incinerated or burned with other fuels in Finland in 2002. Most of the waste combustion is based on commercial packaging waste. There is only one waste incineration plant for mixed waste in Finland (Turku, $50000 \mathrm{t} / \mathrm{a}$ ). Waste materials have been used in energy production as co-combustion fuels at several energy production and utilization plants. The waste has been mixed mostly with biofuels like wood chips, sawdust, bark and peat. Often the fraction of waste has been kept rather small (5-20\% of the energy production) to avoid problems in the operation of the plant and in reaching the emission limits. The experiences of co-combustion have been mainly positive. The fuel conveying, pre-treatment and supplying systems of the biofuel plants can be applied quite easily for co-combustion purposes. Slagging and fouling problems have been usually small and the emissions have not increased remarkably from the use of biofuel only. There are more than 150 biofuel-using boilers which could use solid recovered fuels (SRF) together with the main fuel [2]. Most cities and villages in Finland have a district heating network which offers a lot of heat load for the utilization of the energy content of waste. The district heating boilers that use solid fuels are often in the size range of 1-10 MW. There are also several large utility boilers of the forest industry that produce steam for pulp and paper production using the wood residues of the process. SRF based on municipal, commercial and industrial waste has been used in many of these boilers as co-fuel. There have been several technology development projects on the cocombustion of SRF and biofuels in Finland, and the results have been promising. Cocombustion of biofuels and waste-derived fuels has been found to be advantageous for Finland also because Finland is a sparsely populated country where the transportation distances become very long if the treatment of waste is centralized in large units.

The waste incineration directive (2000/76/EY) and a national waste incineration decree (VNa $362 / 2003$ ) came into force on the $1^{\text {st }}$ of June 2003 for new plants and will come into force in the end of 2005 for old boilers using waste-based materials as fuels. The most important technical demands of the new legislation are the following:

- The gas resulting from the process has to be raised, after the last injection of combustion air, even under the most unfavourable conditions, to the temperature of $850{ }^{\circ} \mathrm{C}$ for two seconds.

- Each line of the incineration plant must be equipped with at least one auxiliary burner. This burner has to switch on automatically when the temperature of the combustion gases after the last injection of combustion air falls below $850{ }^{\circ} \mathrm{C}$.

- Incineration and co-incineration plants must have and operate an automatic system to prevent waste feed:

(a) at start-up, until the temperature of $850^{\circ} \mathrm{C}$,

(b) whenever the temperature of $850^{\circ} \mathrm{C}$ is not maintained,

(c) whenever the continuous measurements show that any emission limit value is exceeded.

- Continuous measurements of $\mathrm{NOx}, \mathrm{CO}$, total dust, TOC, $\mathrm{HCl}, \mathrm{HF}, \mathrm{SO}_{2}$.

- Continuous measurements of the temperature at representative point of the combustion chamber, concentration of oxygen, pressure, temperature and water vapour content of the exhaust gas.

- At least two measurements per year of heavy metals, dioxins and furans. [4] 
Fulfilling the technical demands would cause major changes to most of the existing boilers and power plant processes, although their emissions would be below the limit values of the waste incineration directive. The changes are costly and can make it unprofitable to continue the utilization of waste in the existing plant. It seems now that co-combustion of SRF with biofuels will be finished in most of the plants which have done it. The future trend is said to be in building centralized incineration of waste, even though the advantages of distributed utilization of waste in energy production has been noticed.

Globally, thermal treatment and energy utilization of waste is mostly carried out in large centralized incineration plants which normally use only waste materials as fuel and produce electricity with a relatively low efficiency. Only a few studies and technology development projects have been implemented concerning distributed energy production using wastederived fuels. Examples of these are introduced in the following chapters.

VTT (Technical Research Centre of Finland) has developed a fixed-bed gasification technology for biomass residues and waste-derived fuels with the company Condens Oy in Finland during the late 90 's and the beginning of the $20^{\text {th }}$ century. The size range of the technology is $3-20 \mathrm{MW}_{\mathrm{th}}$. It can be used for district heating and CHP production. Electricity can be produced with an internal combustion engine after catalytic removal of tar compounds from the product gas. Municipal solid waste (MSW) -based SRF, sewage sludge, furniture residues and demolition wood has been demonstrated with the pilot scale plant [5]. The technology has not been commercialized for waste-derived fuels.

Tokyo Institute of Technology has developed waste-to-energy technology for small-scale applications. The waste treatment capacity of the plants varies from 0.5 to $20 \mathrm{t} / \mathrm{d}$, and the electricity production capacity from 20 to $2000 \mathrm{~kW}$. The technology is based on pyrolysis of waste and gasification of the solid residue from pyrolysis. The product gas is treated with a high temperature steam-air mixture to convert the tar compounds to gas. After dust separation and scrubbing the gas is utilized in diesel engines for electricity production and in furnaces for the production of reforming steam. The technology has been applied for example for wood chip gasification in the smallest scale $(1 \mathrm{t} / \mathrm{d})$, for chicken manure gasification $(2 \mathrm{t} / \mathrm{d})$, and for MSW and meat and bone meal gasification in the largest scale. In the town of Ichiki in Japan there is a plant which uses $5 \mathrm{t} / \mathrm{d}$ MSW and $10 \mathrm{t} / \mathrm{d}$ meat and bone meal as fuels in the process. The process is designed for the capacity of $20 \mathrm{t} / \mathrm{d}$ and production of $900 \mathrm{~kW}$ of electricity. The technology is still in a demonstration phase. Presently 200 million tones of solid waste is incinerated in Japan. Most of the waste-to-energy plants are large (>200 t/d). In: Power production from waste and biomass IV, VTT Symposium 222, 267-276.

\section{$[6]$.}

In this article we introduce the results of a study concerning the future of the utilization possibilities of local waste materials for small scale district heating or process heating purposes. The study was carried out in a technology program of the National Technology Development Agency of Finland (TEKES) called DENSY. The name of the study was Utilization of Local By-product Streams in Distributed Energy Systems [1] . 


\section{CASE 1: SMALL SCALE CO-COMBUSTION}

The first case includes an existing district heating plant in a small Finnish municipality with 8300 inhabitants. The plant has used local waste materials in energy production for about ten years. Source-separated energy waste is collected from the largest residential buildings,

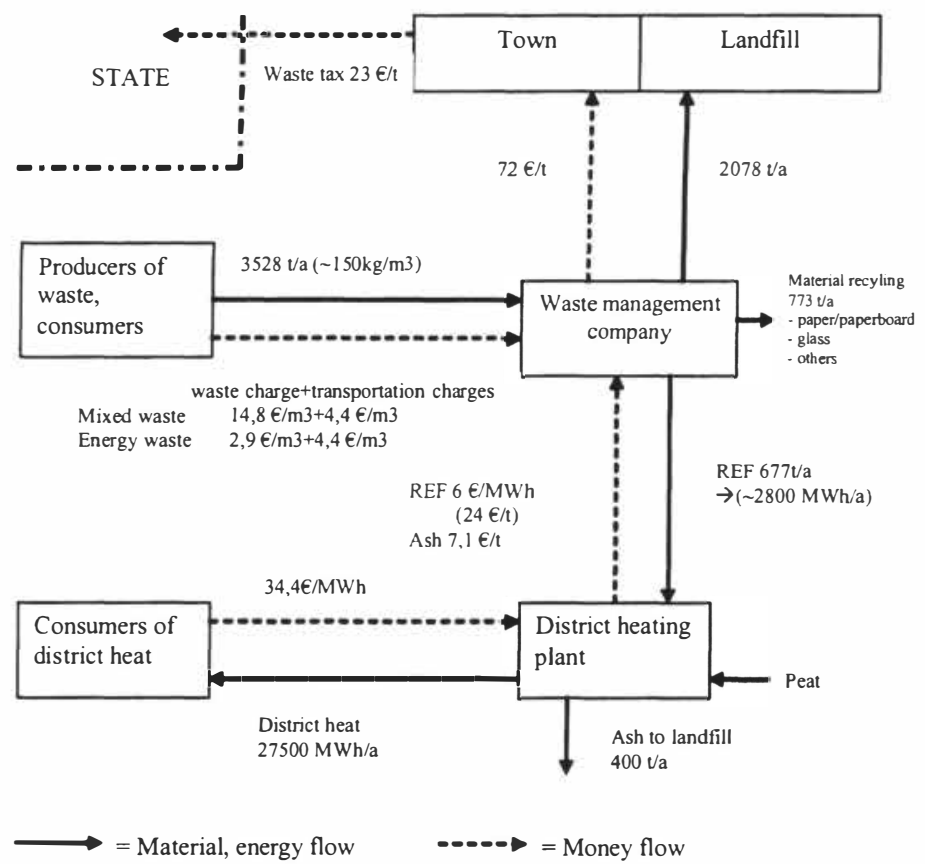

Figure 1. Waste management system, district heating system and material, energy and money flows.

companies and stores. The material is manually checked and crushed in a pretreatment plant by the local waste management company. The recycled fuel is transported to the district heating plant where it is mixed with the main fuel (peat or wood chips) and combusted in a $3.5 \mathrm{MW}_{\text {th }}$ grate furnace. The flue gas is cleaned with a multicyclone and a scrubber. The proportion the recovered fuel (REF) varies between 10 and $20 \%$ of the total energy flow of the fuel mixture. The material, energy and financial flows related to energy waste (2003) are presented above (Figure 1).

\subsection{The effect of co-combustion}

The utilization of REF has not caused any remarkable problems at the district heating plant. The arrangement has been a method to increase the utilization of waste and to lower the expenses of waste management. It has not affected the costs or other preconditions of energy production significantly. The influence of co-combustion on the emissions of the boiler was studied during 1994-1995. Most of the emissions increased clearly when 10-20\% of REF was mixed with peat. However, almost all of the emissions were lower than the limit values in the 
waste incineration directive (see Table 1). Only the amount of particles was higher than the limit. Here the limit values are, however, the values for $100 \%$ waste incineration. The limits for co-combustion could not be determined because there were no instructions for the calculation of the values of a small scale plant. The co-combustion limits would anyway be remarkably higher than the values in the table.

Table 1. Comparison of the flue gas emissions between measured values and limits.

\begin{tabular}{lccc}
\hline & $\begin{array}{c}\text { Reduction } \\
\text { efficiency }\end{array}$ & $\begin{array}{c}\text { Measured, } \\
\text { Peat } / \mathrm{REF}^{3} \text { mixed fuel } \\
{\left[\mathrm{mg} / \mathrm{Nm}^{3}\right]}\end{array}$ & $\begin{array}{c}\text { Emission limits of the } \\
\left(\mathrm{O}_{2}=11 \%\right)\end{array}$ \\
$\begin{array}{l}\text { waste incineration directive } \\
{\left[\mathrm{mg} / \mathrm{Nm}^{3}\right]\left(\mathrm{O}_{2}=11 \%\right)}\end{array}$ \\
\hline Particles & $98 \%$ & 13 & 10 \\
\hline $\mathrm{SO} 2$ & $87 \%$ & 32 & 50 \\
\hline $\mathrm{HCl}$ & $5 \%$ & 265 & 400 \\
\hline $\mathrm{HF}$ & $92 \%$ & 2.4 & 10 \\
\hline $\mathrm{Hg}$ & $79 \%$ & 0.03 & 1 \\
\hline $\mathrm{Cd}$ & $50 \%$ & 0.001 & 0.05 \\
\hline Other trace metals, $\Sigma$ & & 0.017 & 0.05 \\
\hline PCDD/F & $94 \%$ & 0.42 & $0.1 \mathrm{ng} / \mathrm{Nm}^{3}$ \\
\hline
\end{tabular}

\subsection{Demands for the continuation of REF combustion}

If the plant of this case would want to continue co-combustion after the year 2005 it should fulfill all the demands of the waste incineration act. The minimum additional costs in general in the co-combustion plants will be the investments in new emission measurement equipment and the costs of periodic measurements. These costs have been estimated to be about 83000 E/a, which includes the annual payback of the investments and costs of the periodic measurements of trace metal and $\mathrm{PCDD} / \mathrm{F}$ emissions. In small-scale heating plants there are nowadays usually only measurements of oxygen and temperature of the fuel gas.

The district heating plant purchases the REF from the waste management company (see Figure 2). The price for REF is $24 € / \mathrm{t}$. This price has been set equal to the cheapest alternative fuel (peat). The effect of the measurement costs on the financial flows between the waste management company and the district heating plant can be seen in Figure 2. It has been assumed here that the additional costs of REF utilization at the heating plant will be covered by raising the waste management fees. The dramatic change to the present situation, where the waste management company gets paid for the REF, is caused by the small amount of REF. 


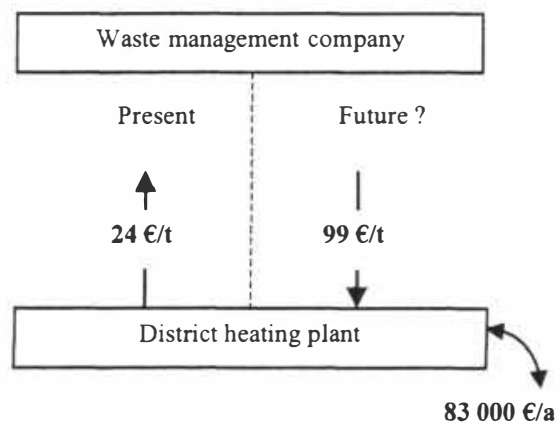

Figure 2. Effect of the emission measurement costs on the financial flows between the waste management company and the district heating plant.

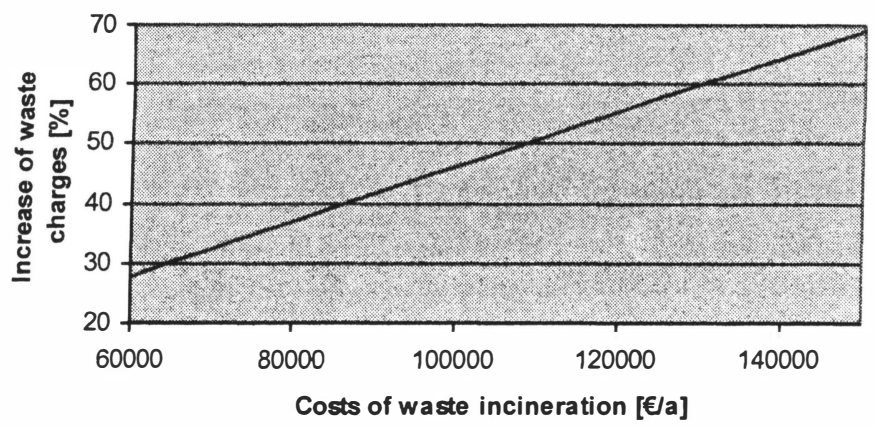

Figure 3. Effect of the additional costs of waste incineration demands on the increase of the waste management fee.

The other costs of the demands of the waste incineration directive (support bumers, automation system for them, additional space for burning to meet the delay time demand and so on) have not been estimated here. The percentual effect of the additional costs to the waste management fee for the waste producers can be seen in Figure 3. For example the total incremental cost of 120000 euros annually would allow an investment of about 390000 euros in addition to the emission measurement systems. The increase in waste charge would then be about $55 \%$.

The increase of the costs caused by the demands of waste incineration legislation is so high in this case that the utilization of REF will probably not be economically feasible in this case after this year. The costs of landfilling will be lower, although also they will be increased in the future. Also the demands of changes to the existing district heating plant are financially and technically very difficult to implement. 


\section{CASE 2: A NEW SMALL SCALE ENERGY-FROM-WASTE PLANT}

The second case was based on a region of three municipalities, which has totally about 75000 inhabitants. In this area the source-separated energy waste is collected from stores (packages), construction sites and some other enterprises. A private company collects the waste, treats it by crushing and transports it to the co-combustion plants. These plants are process heat producing boilers at pulp and paper factories. The transport distance is about $90 \mathrm{~km}$ and the collection distances are between 3 and $20 \mathrm{~km}$. The gate-fee of the energy waste has been 38 $€ / \mathrm{t}$ and the amount about $10000 \mathrm{t} / \mathrm{a}$.

The change of the waste incineration legislation will probably decrease the co-combustion at pulp and paper industry or at least decrease the incomes from the selling of REF. It is still unclear whether it will be possible to utilize REF in the same boilers as presently. The waste incineration permission process can take a long time and the result of it is uncertain. This situation makes it interesting to study the possibility to build a new small scale energy-fromwaste (EfW) plant near the source of the waste.

The quality of the source-separated energy waste has been high. It has contained mainly plastic, wood and such paper and cardboard which cannot be recycled. It is assumed that this kind of high quality REF would be the only fuel used in the new EfW plant. It would be possible to use also biofuels in the boiler if the improvements in recycling decreased the amount of energy waste in future. The capacity of $10000 \mathrm{t} / \mathrm{a}$ for good quality REF means about $40000 \mathrm{MWh} / \mathrm{a}$ as fuel energy and about $7 \mathrm{MW}$ of thermal output for the boilera The boiler was planned for the production of heat for the district heating network or steam for an industrial process.

The investment costs of the EfW plant were estimated with the help of a partner company which manufactures and delivers biofuel-utilizing boiler plants in this size range. It was assumed that the combustion technology would not have to differ a lot from the technology used for biofuels. This estimation was based on the experiences of existing plants using waste-derived fuels. The demands of additional space in the boiler, support burners and their control automation, improved particle separation and emission measurements were estimated to cause in the optimistic case an increase of about $20 \%$ in the investment of the boiler plant. Another partner company which delivers fuel supply and transport systems gave information concerning the investment costs of the energy waste pretreatment equipment. It was assumed that a simple crushing treatment, like previously, would be used.

With the assumptions above the investment for the boiler plant and fuel pretreatment equipment was estimated to be $4.7 \mathrm{M} €$. The variable costs, including personnel, maintenance, electric energy, periodic emission measurements and ash transport and disposal costs, were estimated to be $550 \mathrm{kE} / \mathrm{a}$. When a $5 \%$ interest rate and 15 years' amortization time was used, the total annual cost for the EfW plant would be $1.0 \mathrm{M} €$.

Figure 4 shows the demands for the income (or saving) from energy production and from the gate-fee of the energy waste which are needed to cover the costs of the plant investment and its operation and maintenance. If the plant could get only $10 € / \mathrm{MWh}$ from the heat (approximately the price of biofuel), when sold to the district heating network, the gate-fee of the waste should be $60 € / \mathrm{t}$. Again, if the owner of the plant was an enterprise which needed the heat itself and the purchase price of the heat were $25 € / \mathrm{MWh}$, the costs would be covered without a gate-fee. With the present gate-fee, $38 € /$ t, the energy price should be $15.5 \mathrm{E} / \mathrm{MWh}$. 


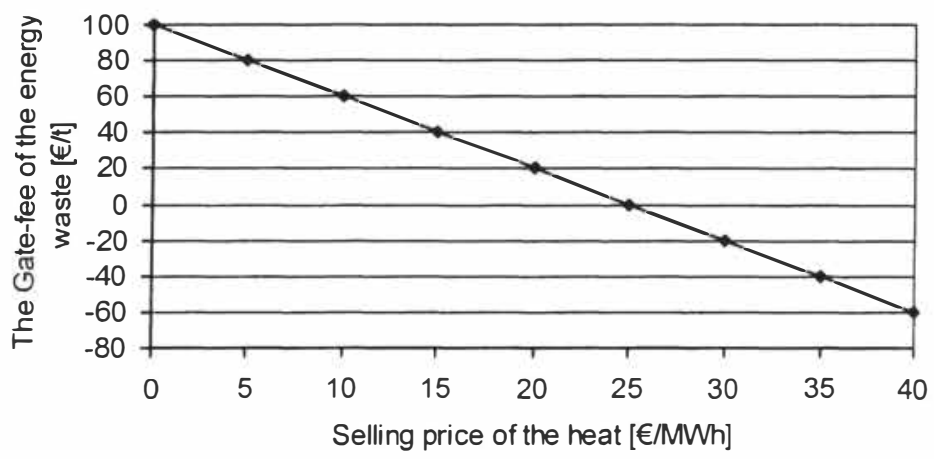

Figure 4. The income demands at the break-eæen point, investment $4.7 \mathrm{M \epsilon}$.

The assumed plant investment was quite optimistic, even though it was received from company experts. Another possibility is to use the rough estimation of $1 \mathrm{M} € / \mathrm{MW}$ for the incineration plant investment. This kind of estimation has been used sometimes for incineration plants. Here the plant is small (usually the specific investment gets higher when the plant size is reduced) but we do not have electricity production, which causes remarkable extra investments. In this case the total annual cost of the plant (fixedat variable) is about 1.3 $\mathrm{M} €$. The corresponding cases at the break-even point for the previous case area

- $10 € / \mathrm{MWh}$ from heat $=>90 € / \mathrm{t}$ gate-fee,

- $25 € / \mathrm{MWh}$ from heat $=>30 € / \mathrm{t}$ gate-fee,

- Present $(38 € / \mathrm{t})$ gate-feea $>24 € / \mathrm{MWh}$ income or saving from heat.

\section{DISCUSSION}

The profitability of waste incineration is strongly influenced by the amount of waste utilized, as the above cases show. The advantage of the co-combustion of normal solid fuels and waste-derived fuel is the possibility to use almost conventional technology and existing boilers. The technical demands of the waste incineration directive can, however, mean major changes to the boiler construction and the auxiliary systems. If the boiler is "loosely" designed so that the delay time can be met, the technical changes to meet the rest of the demands can be done when the amount of waste-derived fuel is so high that the cost advantage of the fuel will cover the investment needs. This can be the case in large industrial boilers, but not often in small district heating furnaces.

The effect of the amount of REF can be illustrated by using for example energy waste flow of $3000 \mathrm{t} / \mathrm{a}$ in case 1 . With the corresponding collection effectivity it would mean a town of about 37000 inhabitants. The boiler capacity should of course be higher, but let us assume that the other conditions are the same. After taking the emission measurement costs in consideration we can make $390 \mathrm{k} €$ investments to the system and still get only a $16 € / \mathrm{t}$ gatefee to cover the increase of costs. This is well below the present costs of the optional treatments of the waste. 
There are also other advantages and disadvantages both in co-combustion and combustion of waste only. These are compared in the list below.

Combustion of waste only:

- The advantage of cheap fuel (or negative price fuel) is maximized, which gives the best possibilities for investment in environmental friendly technologies.

- The unit cost of waste treatment is minimized.

- The investment for combustion of waste or recycled fuel only demands a large area for waste collection, which means high transportation costs.

Co-combustion of waste-derived fuel and biofuela

- Existing boiler plants can be utilized in some cases.

- A lower share of waste-derived fuel needs smaller investments in the flue gas purification to reach the emission limits.

- It is possible that even the waste of one municipality only is treated in one plant. The local energy waste is not enough for the production of district heating, and other fuels are needed.

- It is possible to produce heating in the summer time with a higher share of waste without the storing of waste. There is, however, a danger of too high emissions if the share of SRF is increased in the co-combustion.

- It is possible to treat also sludges without separate investments and fossil support fuel.

- There is more flexibility in the selection of fuels when the plant has been designed for co-combustion. It is possible that the amounts of waste material available for combustion vary a lot because of changes in the market prices of the materials. In case the amount of REF decreases, it is easy to replace it with other fuels.

- Local co-combustion gives also an option for waste management. This can restrain the rising of treatment fees.

Co-combustion can be done in a small and a large scale. In local energy utilization of waste materials the boiler plant is often relatively small in the case of Finland or other sparsely populated countries or regions. Some of the advantages and disadvantages of small scale waste combustion are listed below.

- Heat load is often available in the district heating areas and process industry of small towns. Large cities are more often already covered with district heating capacity.

- There are more options for energy-from-waste plants in small scale applications than in a large scale.

- The efficiency of energy recovery is better in the production of district heating or process heat than in the production of electricity only.

- The utilization of high quality REF (packaging, construction waste) does not cause as much local problems (odors, pest problems) as utilization of all the MSW suitable for combustion.

- It is possible to treat also waste water sludge in the same plant (at least with fluidized bed technology). No fossil support fuel is needed for the combustion of sludge. Thermal drying of sludge is not necessarily needed when SRF is used as support fuel.

- It is possible to integrate the treatment of local industrial energy waste with municipal energy waste.

- In small scale applications it is not usually economical to invest so much in emission reduction technologies. This fact restricts the quality of the waste-derived fuel to the best fractions. There has to be some other treatment (transport to larger plants or landfilling) for the rest of the solid waste which cannot be recycled. 


\section{CONCLUSIONS}

The co-combustion of SRF and domestic solid fuels has been successfully realized in Finland. The new legislation will change the practice a lot. The technical demands of the waste incineration directive and the Finnish waste incineration act will make it economically impossible for many existing co-combustion plants to continue the utilization of wastederived fuels. There will be only few boilers which can continue it after the turn of the year. The amount of utilization of the energy content of waste will decrease a lot for a few years.

The future of energy-from-waste is predicted to be in centralized treatment. The economy of large plants is usually better than that of small plants, but it is still rational in some cases to utilize local waste materials for district heating or process heating purposes in small municipalities. In some regions the district heating capacity of the largest town in the region is filled and it can be more economical to utilize the energy waste in smaller plants which offer heating load for high efficiency energy production for heating purposes. Local EfW plants also offer possibilities for local waste water sludge treatment. The amount of utilized energy waste has to be high enough (thousands of tonnes per year) so that the additional costs of using waste materials as fuel can be covered with the saving in fuel costs. Small $\left(<10 \mathrm{MW}_{\mathrm{th}}\right)$ existing co-combustion boilers can usually not use waste-derived fuels anymore after end of the 2005, but there is market for new small scale energy-from-waste plants. It is possible that the societal acceptability of small scale EfW plants will be more easily achieved than that of large plants which have problems in getting the construction projects started.

\section{ACKNOWLEDGEMENTS}

The financing for the study was offered by the National Technology Agency of Finland, TEKES, which is gratefully acknowledged. Case study 2 was calculated by Antti Koski, who did his Master's thesis in the project. His contribution to the results has also been remarkable.

\section{REFERENCES}

[1] Eriksson, N., Horttanainen, M., Koski, A., Marttila, E., Määttä, K., Peltola, P., Aatamila, M.-L., Ruuskanen J., 2004. Paikallisten sivuainevirtojen hyödyntäminen hajautetuissa energiajärjestelmissä (Utilization of local by-product streams in distributed energy systems). Research report En B-158, Lappeenranta University of Technology (in Finnish).

[2] Sipilä, K., 2002. Overview of Finnish waste to energy R\&D programme. In: Power production from waste and biomass IV, VTT Symposium 222, 33-45.

[3] Alakangas, E. (2000): Suomessa käytettävien polttoaineiden ominaisuuksia. VTT tiedotteita 2045, VTT Energia, Espoo.

[4] Directive 2000/76/EC of the European Parliament and of the Council of 4 December 2000 on the incineration of waste.

[5] Kurkela E., Gasification of waste-derived fuels - R\&D activities at VTT. Ina Power production from waste and biomass IV, VTT Symposium 222, 267-276.

[6] Yoshikawa K., R\&D and Commercialization of Distributed Power and Hydrogen Generation from Solid Wastes Using High Temperature Air and Steam. In: Proceedings of the 6th International Symposium on High Temperature Air Combustion and Gasification, $17^{\text {th }}-19^{\text {th }}$ Oct, 2005, Essen, Germany. 